\title{
KOMUNIKASI DALAM IMPLEMENTASI KEBIJAKAN PENERIMAAN PESERTA DIDIK BARU (PPDB) ZONASI DI SEKOLAH MENENGAH PERTAMA (SMP) KABUPATEN KEDIRI
}

\author{
Aullia Rahmawati \\ Muflihatin \\ Sekolah Tinggi Agama Islam Negeri Kediri \\ atusaira882@gmail.com
}

\begin{abstract}
Student acceptance is the most urgent thing in the education process. thus a PPDB system is needed. the purpose of this study is to analyze Permendikbud policy no. 17 of 2017. The approach used in research is qualitative. This type of research is a case study with the object of research is 1 Kepung Junior High School. Data collection techniques in this study through observation, interviews and also documentation. The data analysis technique used is the Miles, Huberman and Saldana (2012) data analysis model, namely by reducing data, presenting data, and drawing conclusions. The data validity test used is the credibility test through source triangulation and data collection techniques. The results of this study indicate that: the PPDB zoning policy has been communicated by the Department of Education and Sports in the district of Kediri to the implementation of the policy, namely the principal and the school organization. Communication is carried out through transmission, clarity, consistency in the socialization of the zoning PPDB policy in SMP Kediri district. The zoning PPDB policy in Kediri district in the academic year 2017/2018 was only applied to the high school education level and its equivalent because the governing high school policy was the Provincial Education Office, whereas for the junior high school education level and equivalent it had not implemented the zoning PPDB policy in accordance with Kediri district regulations. In the 2017/2018 academic year the PPDB zoning policy was still only for high schools and vocational high schools, whereas in junior high schools there was no enforcement. But for the 2018/2019 academic year the PPDB zoning policy is still a discourse that will be formulated through consultation with relevant parties.
\end{abstract}

Keywords: zoning, acceptance of new students

\begin{abstract}
Abstrak: Pernerimaan peserta didik merupakan hal yang paling urgen proses pendidikan. dengan demikian dibutuhkan sebuah sistem PPDB. maka tujuan penelitian ini untuk menganalisis kebijakan Permendikbud no. 17 tahun 2017. Pendekatan yang digunakan dalam penelitian adalah kualitatif. Jenis penelitian adalah studi kasus dengan objek penelitian yaitu SMPN 1 Kepung. Teknik pengumpulan data dalam penelitian ini melalui observasi, wawancara dan juga dokumentasi. Teknik analisis data yang digunakan adalah model analisi data Miles, Huberman, dan Saldana (2012), yaitu dengan reduksi data, penyajian data, dan penarikan kesimpulan. Uji keabsahan data yang digunakan adalah uji kredibilitas melalui triangulasi sumber dan teknik pengumpulan data. Hasil penelitian ini menunjukan bahwa: kebijakan PPDB zonasi telah di komunikasikan oleh pihak Dinas Pendidikan dan Olahraga kabupaten Kediri kepada pelakasana kebijakan yaitu kepala sekolah dan pihak organisasi sekolah. Komunikasi yang dilakukan melalui tranmisi, kejelasan, konsistensi dalam sosialisasi kebijakan PPDB zonasi di SMP kabupaten Kediri. Kebijakan PPDB zonasi di kabupaten Kediri pada tahun ajaran 2017/2018 hanya diberlakukan pada jenjang pendidikan SMA dan sederajat karena yang mengatur kebijakan SMA adalah Dinas Pendidikan Provinsi, sedangkan untuk jenjang pendidikan SMP dan sederajat belum menerapkan kebijakan PPDB zonasi sesuai dengan peraturan daerah kabupaten Kediri. Pada tahun ajaran 2017/2018 kebijakan PPDB zonasi masih hanya untuk SMA dan SMK, sedangkan pada SMP belum ada pemberlakuan. Tetapi untuk tahun ajaran 2018/2019 kebijakan PPDB zonasi masih menjadi wacana yang akan dirumuskan melalui musyawarah dengan pihak terkait.
\end{abstract}

Kata kunci : zonasi, penerimaan peserta didik baru 
Kebijakan pendidikan adalah suatu keputusan yang dibuat berdasarkan nilai dan penilaian yang sesuai dengan tujuan pendidikan agar dapat tercapai dengan maksimal. (Solichin, 2005) Tujuan pendidikan nasional Indonesia termuat dalam undang-undang no. 20 tahun 2002 pasal 3 menyebutkan bahwa pendidikan nasional berfungsi mengembangkan kemampuan dan membentuk watak serta peradaban bangsa yang bermartabat dalam rangka mencerdaskan kehidupan bangsa, bertujuan untuk berkembangnya potensi peserta didik agar menjadi manusia yang beriman dan bertakwa kepada Tuhan Yang Maha Esa, berakhlak mulia, sehat, berilmu, cakap, kreatif, mandiri, dan menjadi warga negara yang demokratis serta bertanggungjawab.

Berdasarkan tujuan tersebut, kementerian pendidikan dan kebudayaan (kemendikbud) Indonesia membuat kebijakan yang bertujuan untuk mencerdaskan kehidupan bangsa dengan cara pemerataan pendidikan. Kemendikbud mengeluarkan peraturan menteri pendidikan dan kebudayaan (permendikbud) no. 17 tahun 2017 tentang PPDB pada taman kanak-kanak (TK), sekolah dasar (SD), sekolah menengah pertama (SMP), sekolah menengah atas (SMA), dan sekolah sederajat lainnya yang digunakan pemerataan. Dalam sistem tersebut calon siswa diwajibkan mendaftarkan diri ke sekolah yang berdekatan atau satu kawasan dengan tempat tinggalnya berdasarkan alamat dalam kartu keluarga (KK). Faktor domisili (zona) menjadi bagian syarat diterimanya calon peserta didik. (Permendikbud, 2017)

Kebijakan yang dikeluarkan oleh pemerintah sebenarnya bagus untuk mencapai tujuan pendidikan nasional yaitu mencerdaskan kehidupan bangsa, karena terhapusnya sekolah favorit dan menjadikan seluruh sekolah menjadi sekolah favorit sehingga tidak ada lagi mutu rendah dari sekolah. Tetapi banyak terjadi kesalahan pahaman dari pelaksana atau pemakai kebijakan ini, yaitu pemerintah setempat, pihak sekolah, dan masyarakat. Adanya perasaan tidak terima karena ketika ingin mendaftar pada sekolah yang jauh dengan kaulitas lebih baik dibandingkan dengan sekolah yang dekat dengan tempat tinggalnya tidak lolos dalam seleksi penerimaan peserta didik baru dengan adanya sistem zonasi. Perpindahan dari SD ke SMP, ketika seorang anak yang memiliki kecerdasan yang lebih ingin mendaftar ke sekolah yang terkenal dengan favorit untuk dapat menunjang kecerdasan yang lebih oleh anak tersebut, tetapi sekolah favorit bertempat jauh dari tempat tinggal mereka, sehigga mereka beranggapan bahwa sistem zonasi akan membatasi ruang gerak, kemudian mereka mendaftar di SMP yang jarak tempat tinggal dengan sekolah hanya beberapa kilometer saja.

Berdasarkan masalah yang telah dipaparkan diatas, yaitu terjadinya kesalahan dalam pemahaman atau miskomunikasi dari kejelasan kebijakan PPDB zonasi. Sehingga, membutuhkan suatu keberhasilan dari komunikasi yang dilakukan oleh pemerintah kepada pengguna kebijakan. Komunikasi dengan orang tua siswa juga aspek penting yang perlu dilakukan dalam penerapan zonasi. (Beaven, 2003)

Memahami masalah komunikasi diatas, menurut (Agustino, 2006) komunikasi merupakan salah satu variabel penting yang mempengaruhi implementasi kebijakan publik, komunikasi sangat menentukan keberhasilan pencapaian tujuan dari implementasi kebijakan publik.

(Schramm, 1954) menyatakan bahwa komunikasi adalah sebagai suatu proses berbagi (sharing proses). Scrarm menguraikan, "komunikasi berasal dari kata-kata (bahasa) laltin communis yang berarti umum (Common) atau bersama. Apabila kita berkomunikasi, sebenarnya kita sedang berusaha menumbuhkan suatu kebersamaan (commoness) dengan seseorang yaitu kita berusaha berbagi informasi, ide, sikap". (Suprapto, 2006)

Sebuah komunikasi yang efektif adalah komunikasi yang berhasil melahirkan kebersamaan, kesepahaman antara sumber dengan penerima (audience-receiver) nya (Mugambwa, 2018). Sebuah komunikasi akan benarbenar efektif apabila audience menerima pesan, pengertian dan lain-lain persisi sama seperti apa yang dikehendaki oleh 
penyampai.(Invention, Remo, State, Remo, \& State, 2016)

Maka dalam penelitian ini akan membahas dua hal, yaitu pemahaman kebijakan PPDB zonasi di SMP kabupaten Kediri melalui komunikasi, alasan diberlakukan dan tidak diberlakukannya kebijakan PPDB zonasi di SMP kabupaten Kediri sesuai dengan permendikbud no. 17 tahun 2017.

\section{METODE}

Berdasarkan masalah dan tujuan penelitian, penelitian ini menggunakan pendekatan kualitatif deskriptif yaitu penelitian tentang data yang dikumpulkan dan dinyatakan dalam bentuk kata-kata dan gambar, kata-kata disusun dalam kalimat, misalnya kalimat hasil wawancara antara peneliti dan informan.(Sugiyono, 2012) Jenis penelitian yang digunakan adalah studi kasus. Lokasi penelitian yang digunakan adalah di kantor Dinas Pendidikan dan Olah Raga Kabupaten Kediri dan SMPN 1 Kepung. Teknik pengumpulan data yang digunakan yaitu melalui observasi, wawancara dan juga dokumentasi. Informan dalam penelitian ini adalah pihak dari dinas pendidikan kabupaten Kediri dalam bidang kurikulum SMP dan juga kepala sekolah SMPN 1 Kepung. Uji keabsahan data menggunakan triangulasi sumber.

Teknik analisi data yang digunakan adalah model analisi data (Cresswell, 2010), yaitu dengan kondensasi data, penyajian data, dan penarikan kesimpulan. Reduksi data berarti merangkum dan memilah-milah data sesuai dengan kategori pertanyaan, memilih data yang dianggap penting dan menyisihkan datadata pelengkap. Setelah data direduksi peneliti menyajikan data yaitu dapat berupa uraian singkat, tabel, foto cetak dan sejenisnya. Proses secara mendalam dan mengambil inti dari hasil penelitian.(Riyanto, 2007) Informan dalam penelitian ini berjumlah 3 orang meliputi : kepala kurikulum seksi SMP dan dua orang staf kurikulum seksi SMP.

Uji keabsahan data yang digunakan adalah uji kredibilitas (melalui triangulasi sumber dan teknik pengumpulan data), uji transferability (melalui penyusunan hasil penelitian dengan rinci, jelas, dan sistematis), uji dependability (melalui audit keseluruhan proses penelitian), sertauji confirmability (melalui publikasi hasil penelitian).

\section{HASIL DAN PEMBAHASAN}

Hasil penelitian yang dipaparkan merupakan hasil analisis dan validasi dan sudah merupakan hasil proses kondensasi dari Dinas Pendidikan dan Olahraga Kabupaten Kediri yang menjadi objek penelitian. Hasil penelitian terbagi atas dua bagian. Bagian pertama terkait kebijakan PPDB zonasi di SMP kabupaten Kediri melalui komunikasi, sedangkan bagian kedua terkait alasan pemberlakuan atau tidak berlakunya kebijakan PPDB zonasi di SMP kabupaten Kediri.

\section{Pemahaman Kebijakan PPDB Zonasi melalui komunikasi}

Komunikasi

(Communication), merupakan proses penyampaian informasi dari komunikator kepada komunikan. Sementara itu, komunikasi kebijakan berarti merupakan proses penyampaian informasi kebijakan dari pembuat kebijakan (policy makers) kepada pelaksana kebijakan (policy implementors)(Widodo, 2010)

Menurut pandangan Edwards (1980) informasi kebijakan pendidikan perlu disampaikan kepada pelaku kebijakan agar pelaku kebijakan dapat mengetahui, memahami apa yang menjadi isi, tujuan, arah, kelompok sasaran kebijakan agar tujuan dan sasaran kebijakan dapat dicapai sesuai dengan yang diharapkan secara jelas dan konsisten. Jika tujuan dan sasaran kebijakan tidak jelas atau tidak diketahui sama sekali oleh kelompok sasaran akan menimbulkan resistensi dari kelompok sasaran.

Kebijakan PPDB ini diatur dalam permendikbud no. 17 tahun 2017 tentang PPDB pada tingkat TK, SD, SMP, SMA dan bentuk lain yang sederajat, yang ditandantangani pada 5 Mei 2017 yang diterapkan pada masa pendaftaran JuniJuli 2017. PPDB ini dimuat pada pasal 15, 16, dan 17. Tetapi pasal yang dapat digunakan untuk umum atau semua 
jenjang pendidikan, kecuali jenjang pendidikan SMK adalah pasal 15, sedangkan pasal 16 dan 17 hanya dapat digunakan untuk jenjang pendidikan SMA, SMK dan sederajat.

Berdasarkan Permendikbud no. 17 tahun 2017 dinas pendidikan dan olah raga kabupaten Kediri sudah melakukan sosialisasi yang dihadir oleh perwakilan sekolah masing-masing dua orang, yaitu kepala sekolah dan pihak organisasi sekolah. Sebelum dilakukan sosialisasi, pihak dinas pendidikan mengirim surat pemberitahuan kepada pihak sekolah bahwa akan diadakan pertemuan atau sosialaisasi terkait kebijakan PPDB Zonasi 2017. Sosialisasi dilakukan pada hari kamis tanggal 23 Nopember 2017, di Aula Dinas Pendidikan dan Olahraga Kabupaten Kediri. Isi dalam kebijakan PPDB zonasi adalah terdapat dalam permendikbud no 17 tahun 2017 pasal 15, 16 dan 17, di dalam kegiatan sosialisasi tersebut, menjelaskan bahwa ada kebijakan baru dari kementrian Pendidikan yang berupa permendikbud no. 17 tahun 2017 dengan pasal 15, 16 dan 17. tujuan ditetapkan kebijakan baru tentang PPDB yaitu zonasi adalah adanya pemerataan kecerdasan siswa yang berupa pembebasan memilih sekolah yang diinginkan siswa. Sasaran yang dituju oleh kebijakan PPDB zonasi adalah semua jenjang pendidikan mulai dari TK, SD, SMP, SMA, SMK dan sederajat. Strategi dan metode yang digunakan dalam pelaksanaan sosialisasi kebijakan oleh dinas pendidikan dan olahraga kabupaten Kediri adalah presentasi sedangkan media yang digunakan adalah pemaparan materi melalui layar proyektor dan laptop, sehingga audien dari sosisalisasi tersebut dapat melihat dan memahami secara jelas dari apa yang disampaikan.

Berdasarkan hasil penelitian, adanya sosialisasi yang dilakukan oleh pihak dinas pendidikan menunjukan bahwa ada kejelasan dalam kebijakan PPDB zonasi berupa isi, tujuan dari kebijakan, alasan ditetapkannya kebijakan, sasaran yang dituju oleh kebijakan. sehingga penelitian telah menunjukan bahwa komunikasi yang dilakukan memperhatikan tiga aspek utama, yaitu: 1) tranmisi// penyampaian kebijakan atau yang sering disebut dengan sosialisasi; 2) kejelasan dalam komunikasi kebijakan PPDB zonasi; 3) konsistensi dalam sosialisasi kebijakan PPDB zonasi di SMP kabupaten Kediri.

Hasil penelitian diatas sesuai dengan pernyataan (Makinde, 2017) "Communication is an essential ingredient for effective implementation of public policy. Through communication, orders to implement policies are expected to be transmitted to the appropriate personnel in a clear manner while such orders must be accurate and consistent. Inadequate information can lead to a misunderstanding on the part of the implementors who may be confused as to what exactly are required of them".

Menurut teori komunikasi merupakan salah satu faktor penting dalam menjalankan suatu implmentasi agar berjalan secara efektif untuk menerapkan kebijakan publik bila ukuran-ukuran dan tujuan-tujuan dipahami secara jelas oleh personal yang bertanggung jawab dalam kinerja kebijakan.(Marume, Mutongi, Madziyire, Easton, \& Frawley, 2016) Informasi yang disampaikan bersifat akurat dan konsisten karena informasi yang tidak memadai dapat menyebabkan kesalahpahaman dari pihak pelaksana yang mungkin bingung mengenai apa yang sebenarnya dibutuhkan dari mereka. Dengan adanya proses komunikasi ini tercipta pemahaman tentang peraturan yang mengatur prosedur penerimaan agar mudah dimengerti oleh panitia sehingga informasi yang diberikan pada calon pendaftar sangatlah cukup baik dan mudah dimengerti.(Kittler, Rygl, \& Mackinnon, 2011)

Communication is the first requirement for effective policy implementation is that those who are implement a decision must know what they are supposed to do. Policy decisions and implementation orders must be transmitted to appropriate personal before they can be followed. Naturally, these communications need to be accurate, and they must be accurately perceived by implementors. Many obstacles lie in the path of transmission of implemetation communications" .(Fryde, 2018) 
Selaras dengan teori Makinde menururt (Hall, Hall, \& Hall, 1956), komunikasi merupakan syarat pertama untuk implementasi kebijakan yang efektif adalah bahwa mereka yang menerapkan keputusan harus tahu apa yang seharusnya mereka lakukan. Keputusan kebijakan dan perintah pelaksanaan harus dikirim ke personal yang sesuai sebelum dilakikanya tindakan. Tentunya komunikasi perlu akurat dan harus dipahami secara akurat oleh pelaksana. Banyak hambatan terletak pada jalur transmisi dari komunikasi implementasi (pelaksanaan).(Kelvin-iloafu, 2016)

Pernyataan tersebut dimaksud suatu kebijakan bisa dilaksanakan dengan baik apabila konsistensi informasi yang disampaikan bagi pelaksananya jelas. Komunikasi menentukan keberhasilan pencapaian tujuan dari implementasi kebijakan publik. Implementasi yang efektif akan terjadi bila para pembuat keputusan mengetahui apa yang akan mereka lakukan.(Ikechukwu, 2013) Komunikasi juga harusterjalin diantara para pembuat keputusan dan implementor agar implementor semakin konsisten dalam melaksanakan kebijakan.(Sularto, Wahyudi, \& Sukmawati, 2018)

\section{Alasan Diberlakukan Atau Tidak Diberlakukan Kebijakan PPDB Zonasi Di SMP Kabupaten Kediri}

Sosialisasi yang dilakukan oleh kepala dinas pendidikan dan olahraga kabupaten kediri, menyatakan bahwa kebijakan PPDB zonasi di kabupaten Kediri untuk tahun ajaran 2017/2018 hanya berlaku kepada jenjang pendidikan SMA, SMK dan sederajat saja, untuk jenjang pendidikan SMP belum menggunakan atau menerapkan kebijakan PPDB zonasi yang berupa pemetakan radius zona sekolah tersebut.

Alasan kebijakan PPDB zonasi diberlakukan di SMA karena pemerintahan yang mengatur peraturan dan pemberlakuan kebijakan SMA adalah Dinas Pendidikan Provinsi dan Dinas Pendidikan Provinsi mengatur bahwa sistem PPDB tahun ajaran 2017/2018 dan juknisnya khusus untuk SMA dan SMK untuk menerapkan kebijakan PPDB zonasi sesuai dengan permendikbud no. 17 tahun 2017 pas 15, pasal 16 dan pasal 17. Sedangkan yang mengatur kebijakan di jenjang pendidikan SMP adalah Dinas Pendidikan Daerah, di kabupaten Kediri terdapat peraturan daerah yang menyatakan bahwa SMP pada tahun ajaran 2017/2018 belum memberlakukan kebijakan PPDB zonasi di kabupaten Kediri dan dari juknisnya sendiri tahun 2017/2018 bukan untuk jenjang pendidikan SMP kebawah.

Teknik yang dilakukan dalam kebijakan yang diberlakukan tersebut ialah setiap calon peserta didik diberi kesempatan untuk mendaftar pada sistem PPDB online dengan mengisi kolom pilihan sekolah yang akan dituju sebanyak 3 sekolah. Jika pun calon peserta didik hanya berkenan untuk mengisi satu sekolah saja, tetap diberpolehkan dan sistem PPDB online pun tetap akan berjalan sebagaimana mestinya. Kemudian, jika calon peserta didik dinyatakan di terima oleh sistem PPDB online di suatu sekolah dengan jarak tempuh sekolah dan tempat tinggal sangat jauh, calon peserta didik tidak diperbolehkan membatalkan pendaftaran tersebut.

Kriteria yang ditetapkan untuk dapat diterimanya calon peserta didik baru yaitu berdasarkan nilai siswa dan pretasi siswa. Prestasi yang dapat mendukung diterimanya calon peserta didik baru yaitu lomba FMIPA, olahraga dan seni dengan pemerolehan minimal juara 1, 2, dan 3 tingkat kabupaten Kediri. Semua sistem penerimaan calon peserta didik baru yang mengatur adalah sistem PPDB online, sehingga tidak ada campur tangan dari pihak sekolah. Misalnya dari pengelolaan hasil nilai dan prsetasi calon peserta didik baru semua yang mengolah adalah sistem PPDB online dan yang menentukan di terima atau tidak di terima calon peserta didik baru juga sistem PPDB online.

Sedangkan untuk rencana PPDB tahun ajaran 2018/2019 mendatang, kebijakan PPDB zonasi untuk jenjang pendidikan SMP dan sederajat masih menjadi wacana yang akan dibicarakan pada semester genap mendatang. 
Sosialisasi yang dilakukan pada tanggal 23 Nopember kemarin adalah sosialisasi perdana tentang kebijakan PPDB zonasi yang masih menjadi wacana untuk jenjang pendidikan SMP. untuk memutuskan diberlakukannya atau tidak untuk tahun ajaran 2018/2019 masih dibutuhkan musyawarah dengan semua pihak terkait yang agenda pertemuan dengan MKKS dikisarkan setelah bulan Januari-Februari.

\section{KESIMPULAN}

Kesimpulan dari penelitian diatas adalah kebijakan PPDB zonasi telah di komunikasikan oleh pihak Dinas Pendidikan dan Olahraga kabupaten Kediri kepada pelakasana kebijakan yaitu kepala sekolah dan pihak organisasi sekolah. komunikasi yang dilakukan telah memenuhi indikator dari komunikasi yaitu: 1) tranmisi/ penyampaian kebijakan atau yang sering disebut dengan sosialisasi; 2) kejelasan dalam komunikasi kebijakan PPDB zonasi ; 3) konsistensi dalam sosialisasi kebijakan PPDB zonasi di SMP kabupaten Kediri. Kebijakan PPDB zonasi di kabupaten Kediri pada tahun ajaran 2017/2018 hanya diberlakukan pada jenjang pendidikan SMA dan sederajat karena yang mengatur kebijakan SMA adalah Dinas Pendidikan Provinsi, sedangkan untuk jenjang pendidikan SMP dan sederajat belum menerapkan kebijakan PPDB zonasi sesuai dengan peraturan daerah kabupaten Kediri.Pada tahun ajaran 2017/2018 kebijakan PPDB zonasi masih hanya untuk SMA dan SMK, sedangkan pada SMP belum ada pemberlakuan. Tetapi untuk tahun ajaran 2018/2019 kebijakan PPDB zonasi masih menjadi wacana yang akan dirumuskan melalui musyawarah dengan pihak terkait.

\section{DAFTAR RUJUKAN}

Agustino, L. (2006). Dasar dasar kebijakan publik. Bandung: Alfabeta.
Beaven, C. Parental Choice or school choice: who benefits from the removal of zoning? , (2003).

Cresswell, J. W. (2010). Research design (Pendekatan kualitatif, kuantitatif dan mixed). Yogyakarta: Pustaka Pelajar.

Fryde, E. B. (2018). Financial Resources of Edward III in the Netherlands, 1337 40 ( 2nd part ). 40, 1142-1216.

Hall, E. T., Hall, R., \& Hall, E. T. (1956). If SILENT LANGUAGE.

Ikechukwu, B. (2013). The Obstacles To Effective Policy Implementation By The Public Bureaucracy In Developing Nations: The Case Of NigeriA. 2(7), 59-68.

Invention, H., Remo, I., State, O., Remo, I., \& State, O. (2016). The Impact Of Effective Communication On Organizational. 3(3), 1904-1914. https://doi.org/10.18535/ijsshi/v3i3.1

Kelvin-iloafu, L. E. (2016). The Role of Effective Communication in Strategic Management of Organizations. 6(12), 93-99.

Kittler, M. G., Rygl, D., \& Mackinnon, A. (2011). Beyond culture or beyond control ? Reviewing the use of Hall 's high- / low-context concept. https://doi.org/10.1177/147059581139 8797

Makinde, T. (2017). Problems of Policy Implementation in Developing Nations: The Nigerian Experience. Journal of Social Sciences, 11(1), 6369.

https://doi.org/10.1080/09718923.200 5.11892495

Marume, S. B. M., Mutongi, C., Madziyire, N. C., Easton, D., \& Frawley, S. J. (2016). An Analysis of Public Policy Implementation. IOSR Journal of Business and Management, 18(4), 86-93. https://doi.org/10 